\author{
Zalacko Roland \\ Dr. Zöldy Máté \\ Dr. Simongáti Gyözö
}

$\underline{\text { http://dx.doi.org/10.21278/brod72201 }}$

ISSN 0007-215X

eISSN $1845-5859$

\title{
COMPARISON OF ALTERNATIVE PROPULSION SYSTEMS - A CASE STUDY OF A PASSENGER SHIP USED IN PUBLIC TRANSPORT
}

UDC 621.182.3:629.5.03:629.55

Original scientific paper

\begin{abstract}
Summary
The unique feature of river transport is given by the rivers' flow and the changing crosssections of the riverbed. Most river vessels operate with a conventional propulsion system. Engine power should be scaled to the maximum expected power demand, which means that the engine is forced to run at medium or low load, almost always downstream and upstream for part of the operating time. In these cases, the engine's operating point is far from ideal, so there is an increase in specific fuel consumption. This is especially true for ships that are forced to stop and start frequently. An example for the circumstances mentioned above is the BKV-100 type ship operated at Budapest as a public transport vessel. A measurement on a schedule route revealed that with given environmental conditions (water level, river flow rate, etc.), the power installed in the vessel is almost double the maximum power demand measured. Due to this reason and to the differences in power demand of downstream and upstream, it may be technically worthwhile to replace the existing conventional propulsion system with an alternative propulsion system. Based on the measurements, in this paper the authors compare 4 alternative drive systems to the existing one with regards to fuel consumption and the investment costs. Beside this, a simple but effective fuel consumption estimation method and a simple cost-benefit analysis are also described.
\end{abstract}

Keywords: $\quad$ alternative propulsion system; inland navigation; operational profile; cost and fuel consumption estimation

\section{Introduction}

Unlike long sea shipping, inland navigation in many cases operates with variable power loads. The use of full installed engine power is just a small part of the ship's operating time (Fig 1). The distribution of power demand over the entire operating time can be interpreted by the power utilization histogram, also known as the operational profile. The nature of the profile depends on the vessel, the operating conditions, and the environmental conditions.

The propulsion system of a ship that has been in operation for decades will become obsolete over time and increasingly uneconomical to operate. Some ships may also need to operate in task that is completely different from its design purpose. In this case, it may be worthwhile, at least from a technical point of view, if it is feasible, to replace some drive system components or the complete drive system. This requires knowledge of the operational 
profile. In the case of an existing ship, we can measure power utilization directly on the ship. For more accurate and reliable measurement, it is important to measure for a longer period at variable conditions. After assessing the operational profile, several possible configurations need to be considered. However, for an existing vessel there may be several limits. Examples include engine room size limits, number of propeller shafts, and payback time. The first two can also be varied within certain limits, but these will require restructuring, which will increase conversion costs, resulting a longer payback time. With all this in mind and with appropriate weight factors you can decide, whether new drive system would be worthwhile or not.

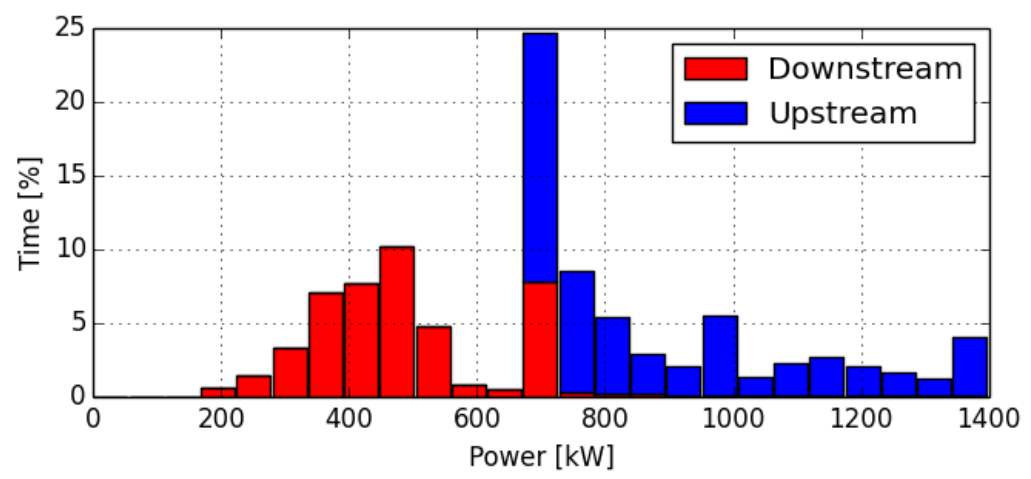

Fig. 1 Operational profile of a cruise ship on Basel-Amsterdam route [1]

One of the most important components of operating costs is fuel consumption. It is generally true that efforts should be made to minimise fuel consumption because via this the increase of profit can be made [2]. In addition to the old traditional propulsion systems, several alternative solutions can be used better to suit the propulsion system to the operational profile. The following will examine a simple cost-benefit analysis of some alternative propulsion systems for an IW passenger ship.

\section{Propulsion energy demand factors in the Budapest section of the Danube}

In waterborne traffic on the Danube, particularly the section of the river covered by the BKV 100 type (Fig. 2, Fig. 3), the following factors may affect the vessel's main engine's energy consumption.

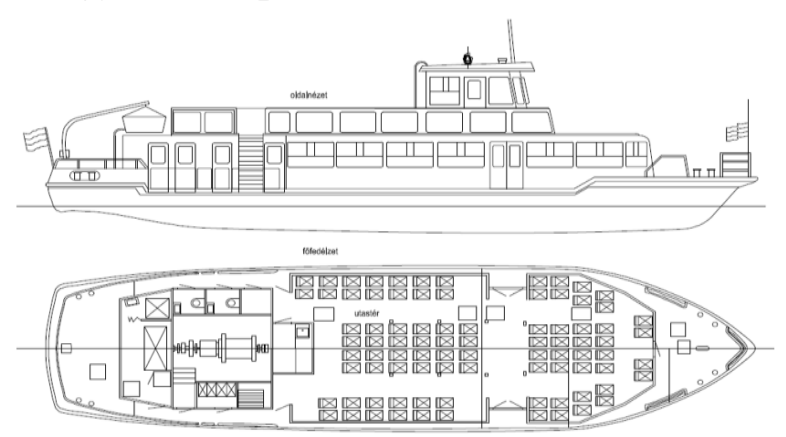

Fig. 2 Drawing of BKV 100 [3]

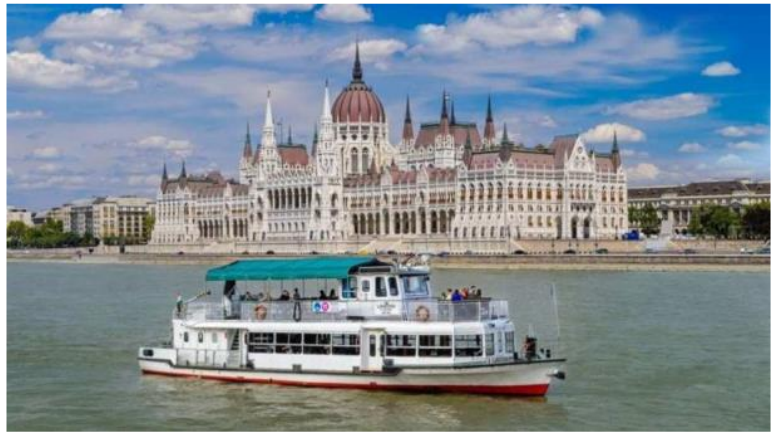

Fig. 3 Photography of BKV 100 [3]

\subsection{Environmental factors}

\subsubsection{Wind, wave}

In general, the effects of wave and wind in river navigation are negligible. Although the measured vessel has a relatively large wind surface, only the north and south winds can generate a more serious positive (booster) or negative (pull back) effect due to the orientation 
of the river. In addition, during a scheduled tour, these effects are more or less balanced, so they don't need to be considered. The waving on the Budapest section does not significantly increase the ship's resistance either.

\subsubsection{Resistance to flowing water}

Unregulated rivers are characterized by flowing water. As a result, moving in the opposite direction to the flow (upstream) will always require more power under a similar load case than when sailing in the direction of the flow (downstream). The river's flow rate depends on the continuous change of water level and the convex and concave nature of the shoreline. The Danube flow rate at Budapest can vary between 500 and $8000 \mathrm{~m}^{3} / \mathrm{s} \mathrm{[4],} \mathrm{and} \mathrm{the}$ water depth difference can exceed 8 meters. The average speed of the river is $1,25 \mathrm{~m} / \mathrm{s}$ here.

\subsubsection{Shallow water resistance}

Another feature of river navigation is the constantly changing water level, which can significantly increase the required power as a result of the shallow water effect. BKV (Budapesti Közlekedési Vállalat) boats run on a very varied course, and in many cases especially during moorings - they run in shallow water. At low water levels almost the entire route can be considered as shallow. Increase in resistance and so power demand can even be detected despite of decreasing flow speed (due to decreasing water level).

\subsubsection{Ship traffic}

Although, the waterways of Western Europe are much busier than the traffic on the Danube, scheduled public transport in Budapest (provided by BKV Zrt.'s line routes between its own pontoon ports) is increasingly influenced by ship traffic on the route and during moorings. There are many freight, cruise, and hotel vessels operating in the narrow stretch of the river. Hence, navigation of public transport vessels is often slowed down and requires more maneuvers, which is in most of the cases compensated by higher cruising speeds. This results in higher engine load and fuel consumption.

\subsection{Operating factors}

\subsubsection{Up- and downstream}

As described in 2.1.2., river ships travel with higher resistance upstream than downstream. On the other hand, in downstream sail, decelerations and turns can also cause higher energy requirements. Meanwhile, the ship rarely travels parallel to the flow of the river, as it is forced to approach ports by zigzagging from one bank of the river to the other. Thus, in almost all cases, its longitudinal axis makes an angle with the flow velocity vector, which further increases its resistance during travel.

\subsubsection{Maneuvers}

The full route consists of 22 to 23 stops, and it is approx. $23 \mathrm{~km}$ long, so they are located on average every $1 \mathrm{~km}$, but in the city center rather every 500 meters on both banks of the river [5]. All this requires a lot of maneuvering. Due to the single screw-straight shaft propulsion system of BKV vessels, the bow of the vessel must always be turned upstream at downstream moorings in order for the vessel to be able to withstand the flow of the river. Leaving the port, boat can re-enter the downstream direction with another relatively highenergy maneuver. All this is coupled with a great waste of time. 


\subsubsection{Load factors}

For most boats, its resistance is mostly determined by its draft, which can vary over a wide range. However, in the case of the BKV-100, the weight load does not significantly change the operating characteristics because the maximum mass of passengers, together with the mass of daily provisions, is not significant compared to the lightship of the vessel (approx. $10 \%)[5]$.

\subsection{Driving factors}

Finally, the vessel's required or appropriate speed, the associated engine load control, fundamentally affects fuel consumption and propulsion system load. The required or appropriate speed of the vessel may also be influenced by environmental characteristics (e.g. fog, wading conditions), but in the case of public passenger vessels the timetable may also be such a controlling factor. In the case of cargo ships, the traffic on the locks, the knowledge of the expected time of transit, or even the possible time of loading also affect the ship's speed. Today, taking all this into account, leads to the so-called "Smart steaming" technologies, the essence of which is to dynamically optimize the ship's speed based on real-time nautical and environmental conditions and information on the port of destination and loading. Due to the factors listed above, it is difficult to control or require the driver to adjust the engine fuel rate (throttle position) for cruise D11. The engine load relies on the captain's experience to determine at which the maneuver will be conducted, and in some cases this may be more than necessary. By choosing the cruising speed the schedule keeping is normative.

\section{BKV-100 case study}

\subsection{Measurement information}

The Budapest University of Technology (BME), Department of Aeronautics, Naval Architecture and Railway Vehicles, performed power and speed measurements on the ship "Lánchíd", in order to record a route diagram and an operational profile on the route of scheduled passenger vessel D11.

Strain gauges suitable for torque measurement were placed on the propeller shaft, right after the engine. The data logger was mounted on a larger diameter part of the shaft using a bracket. This included a unit capable of receiving signals from gauges and shaft rotational speed measuring unit, and a radio frequency transmitter that transmitted the measured data from the rotating shaft immediately to a stationary receiver in the engine room. The receiver was connected directly to a laptop on which the signals could be stored and checked in real time. The measured data were the voltage signal proportional to the deformation of the shaft, i.e. the load torque, and the speed of the shaft. For the duration of the measurement, BME also placed its own GPS transmitter on the ship, with which the current GPS coordinates and the speed of the ship could be measured and recorded.

General data:

1. Engine type: Doosan L126TIM, MEDIUM DUTY, 400 PS (294 kW) 2,100 rpm

2. Main dimensions: $L_{p p}=23.25 \mathrm{~m} ; B_{\max }=6.40 \mathrm{~m} ; D=1.60 \mathrm{~m} ; T_{\max }=0.95 \mathrm{~m}$;

3. Place and date of measurement: Budapest Danube section, 31.01.2018

4. Weather conditions: cloudy, calm weather all day, ice-free water

5. Water level: $344 \mathrm{~cm} \mathrm{[6]}$

6. Ship load: almost empty ship, 5 persons on board 
Before presenting the results obtained, some additional information regarding the measurement circumstances worth to be given. The measurement was made without passengers and the route was ideally completed. This means that the ship stopped at the stations for only half a minute, which is in real conditions always more because of the passengers boarding. A longer exchange of passengers requires a higher speed between stops. Nominal passenger load causes an increase in the ship's draft and thus its resistance and in power demand. However, usage factor is - unfortunately - rather low. On the other hand, on the day of the measurement, the Danube's water level was almost $100 \mathrm{~cm}$ higher $(344 \mathrm{~cm})$ than the average water level in Budapest for the last 15 years $(248 \mathrm{~cm})$. For the last 5 years, over $90 \%$ of the time, the water level was below $344 \mathrm{~cm} \mathrm{[6].} \mathrm{So} \mathrm{the} \mathrm{ship} \mathrm{was} \mathrm{moving} \mathrm{in} \mathrm{a}$ higher water flow than average. Without detailed measurements, it is quite difficult to take these effects into account, but it can be assumed that they balance each other. It can be said that the measurement data show the results of an average route so the average power demand can be estimated without corrections.

The measurements were made on the entire downstream route, and the majority of the upstream route ( 9 of the total 11 sections). Accurate performance data is not available for the missing small part, but for this sections a fairly accurate average upstream energy consumption can be calculated from the measured section's data.

\subsection{The measured operational profile}

\subsubsection{Upstream route diagram}

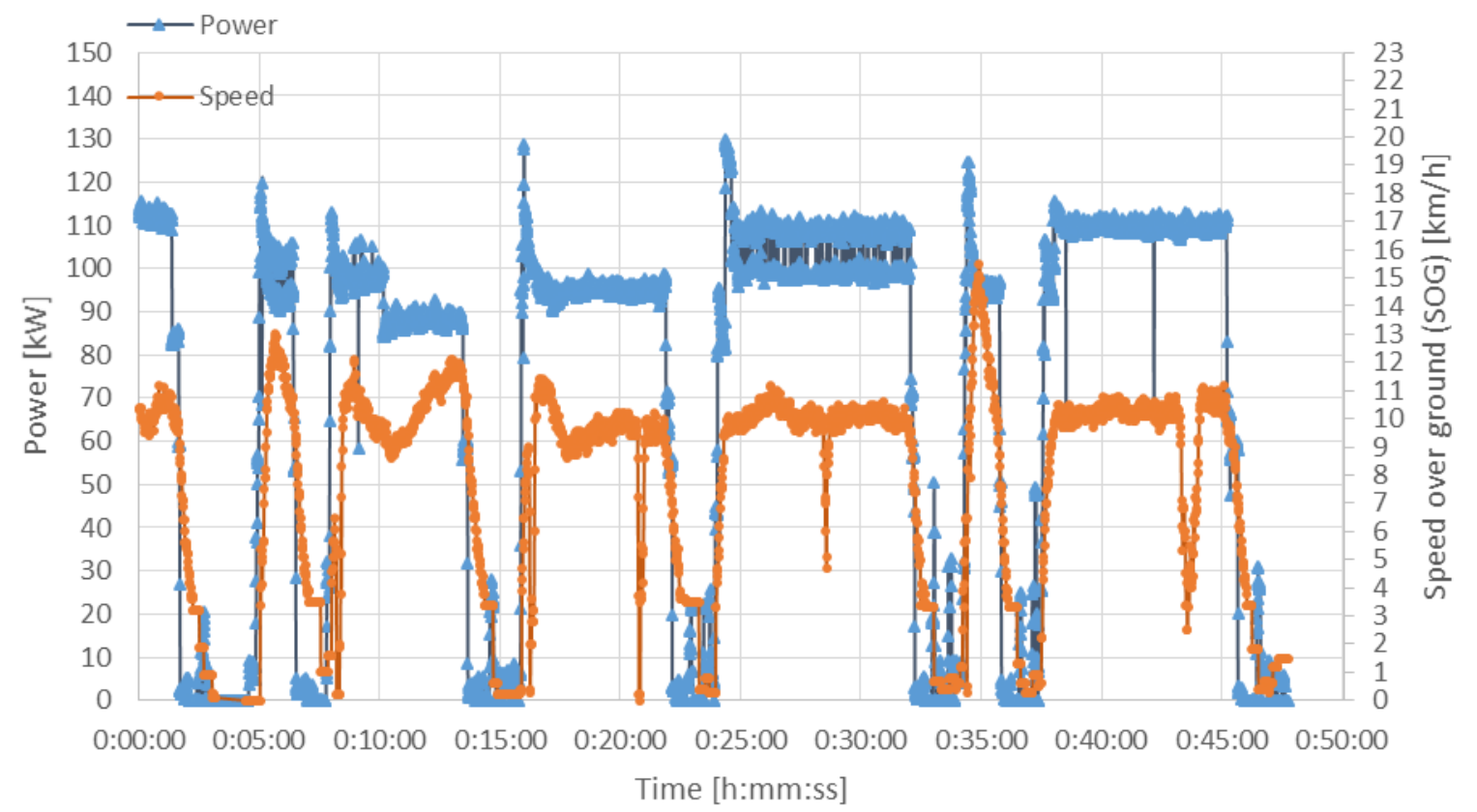

Fig. 4 Upstream route diagram

Fig. 4 shows that power can be divided into 2 relevant ranges. The lower range is up to $30 \mathrm{~kW}$, the upper range is between 85 and $115 \mathrm{~kW}$ based on average values. The power is between 85 and $115 \mathrm{~kW}$ for nearly $2 / 3$ of the total upstream operating time, and for the greater part of the remaining $1 / 3$ of the operating time, the engine runs below $30 \mathrm{~kW}$. This value is presumably displayed due to minor - sometimes even reverse - corrections during mooring maneuvers. Four local peaks are also visible in the $115-130 \mathrm{~kW}$ range due to big accelerations. 


\subsubsection{Downstream route diagram}

The diagram below (Fig. 5) also shows a variety of power utilization, with the maximum value exceeding $95 \mathrm{~kW}$ for only a small fraction of the operating time. It can be seen that just like upstream, the ship's engine operates in a narrow range. It runs between 85$95 \mathrm{~kW}$ for most of the time of downstream route. The local peaks, which can sometimes exceed $140 \mathrm{~kW}$, result from the start against the water flow. The distance between 5 ports is so small that it must suddenly decelerate after the ship reaches cruising speed. We can see that the ship in downstream sailed almost 2 times faster than in upstream. Also we can estimate the water flow speed, which can be $5-6 \mathrm{~km} / \mathrm{h}$. That means a little bit faster than average.

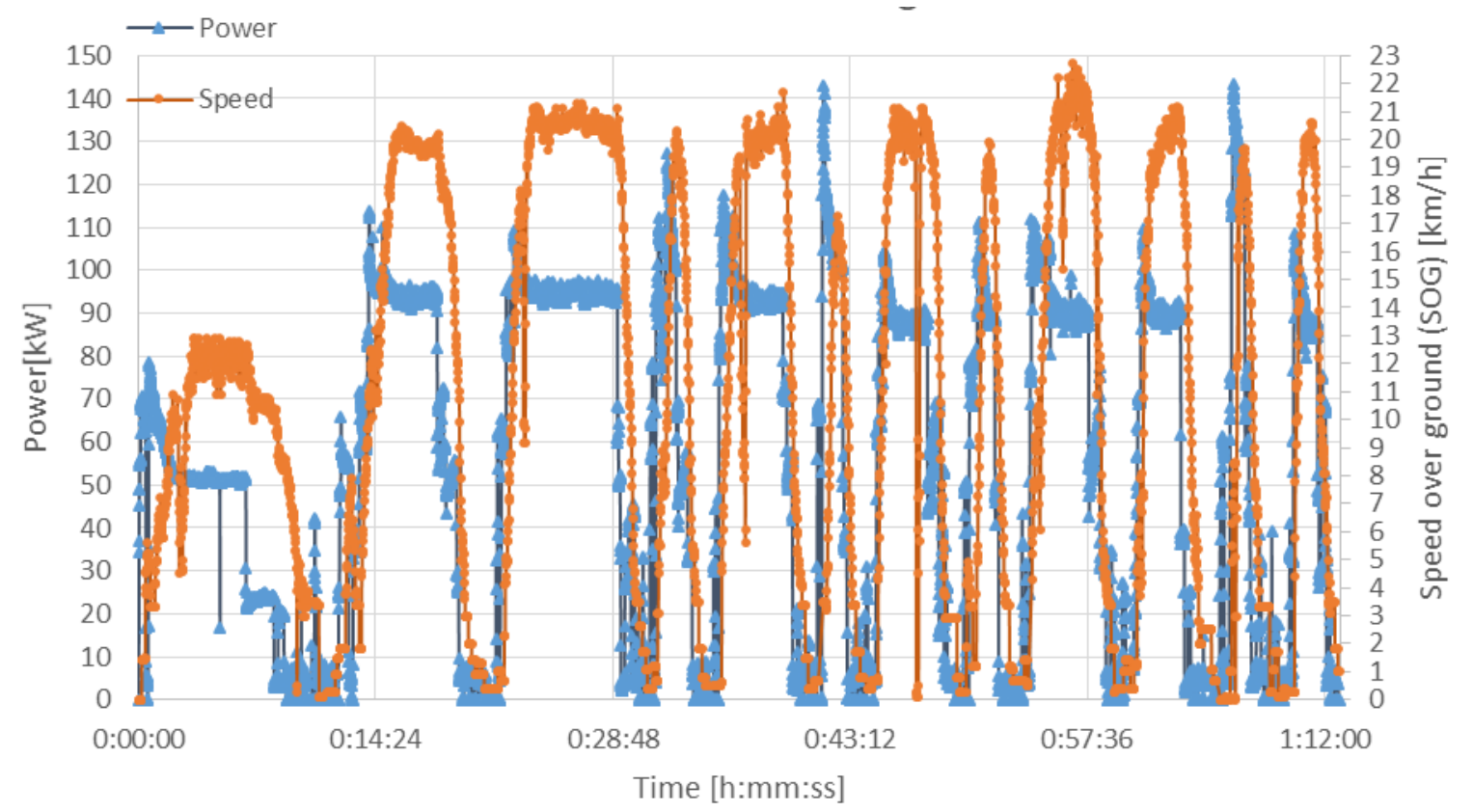

Fig. 5 Downstream route diagram

\subsubsection{Measured operational profile}

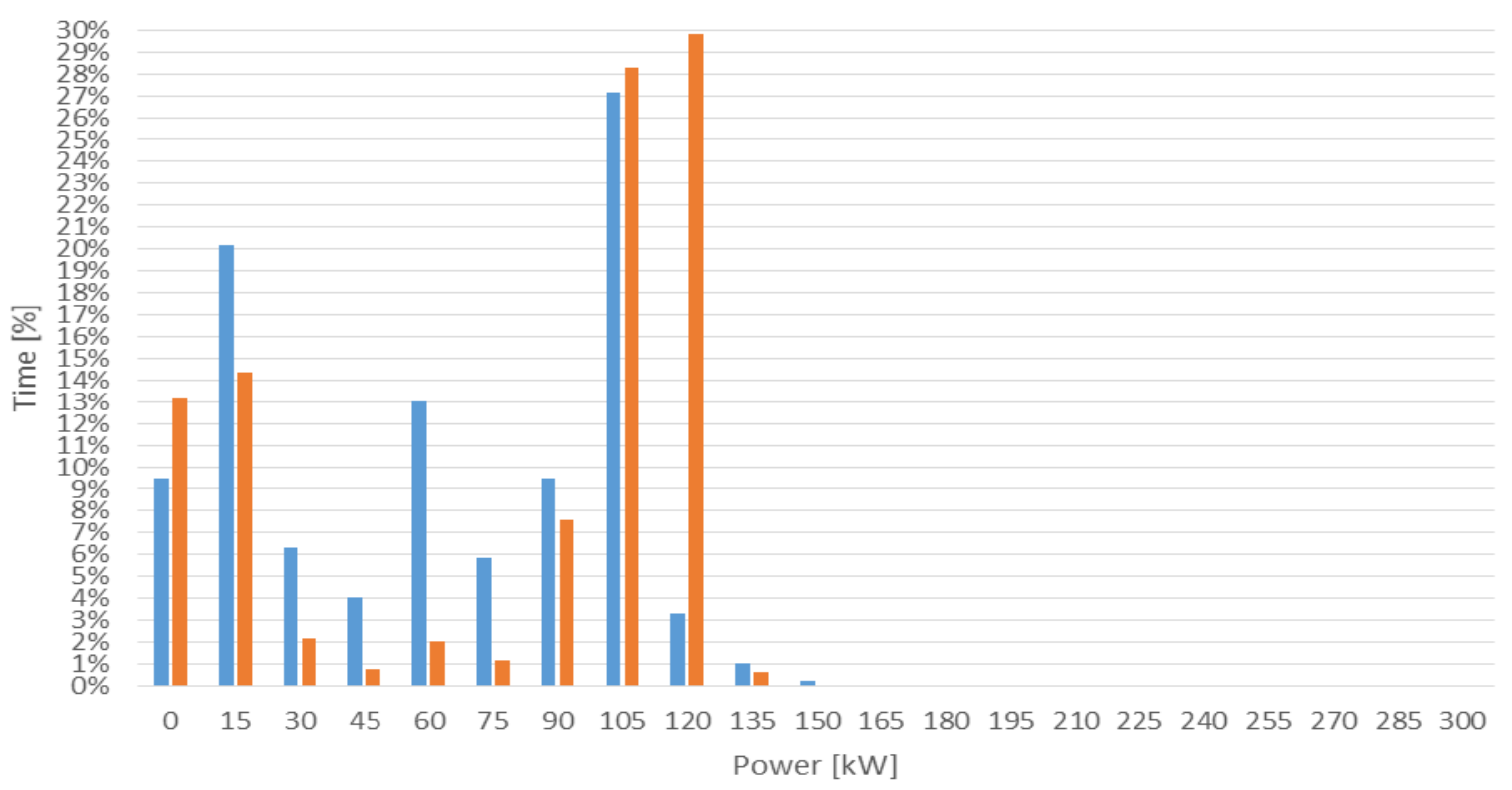

Fig. 6 Operational profile BKV-100 type D11 route (upstream - orange, downstream - blue) 
It can be seen from the diagrams described in the previous two sections that the vessel has sufficient speed upstream and downstream to ensure the current schedule. The vessel's engine is low loaded for the full time. It can also be seen that the engine hardly ever runs above $45 \%$ of maximum power, which can also be attributed to the small distance between stations. From the diagram below (Fig. 6) one can conclude that for most of the operating time the ship requires only extremely low power, so the built-in $294 \mathrm{~kW}$ main engine then operates at very low loads. It is important to emphasize that these conclusions were drawn from measured data related to a given water level and in a schedule in which the vessel needs not to sail very fast between stations. Only the propulsion power was measured during the measurement, but in addition an approx. $5 \mathrm{~kW}$ generator to charge the auxiliary batteries was driven by the engine via a belt drive. This extra power should be added to the engine power at calculations.

\section{Fuel consumption calculations}

Unfortunately, fuel consumption couldn't be measured; therefore only an estimate of fuel consumption can be realized. However, estimation methods allow a comparison of the existing and some alternative propulsion systems. Fuel composition can affect the fuel consumption as well [7], but as during the measurement the same batch was used this effect can be neglected.

\subsection{Estimation possibilities}

The most accurate estimation can be achieved by using the so-called "specific fuel consumption map" or "performance map" (an example is shown on Fig. 7). The curves vary from engine to engine, so each engine has its own fuel map. Such charts are rarely public. Manufacturers usually provide only basic engine data and the (specific) fuel consumption values measured at a few points are reported. Neither the "fuel map" of the original nor a possible new engine was available, so another method was needed.

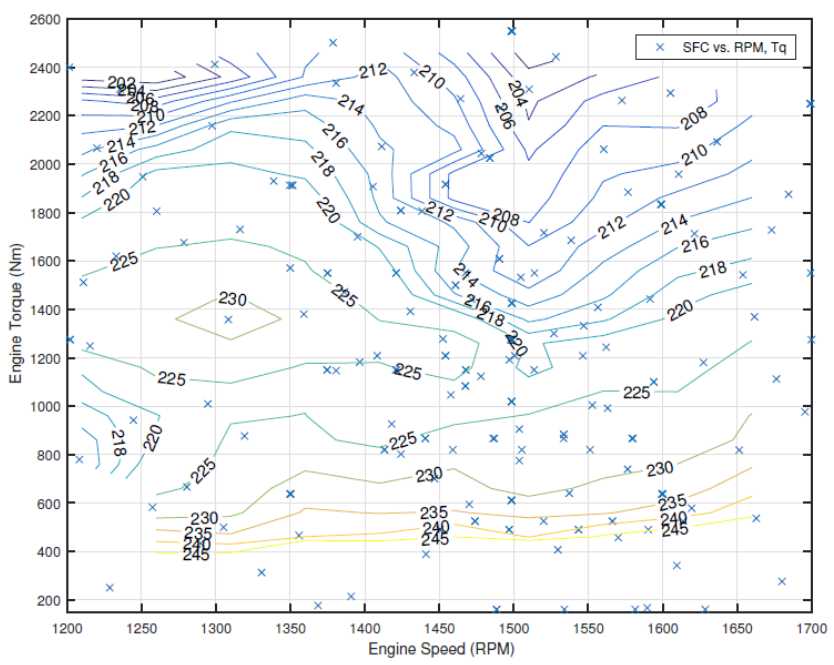

Fig. 7 Fuel map of Perkins 2506C [8]

The method we used was published by Altosole et al. [9]. The process is based on the general data shown on Fig. 8. The diagram shows a general diesel engine's relative performance as a function of relative speed and different fuel consumption levels. 


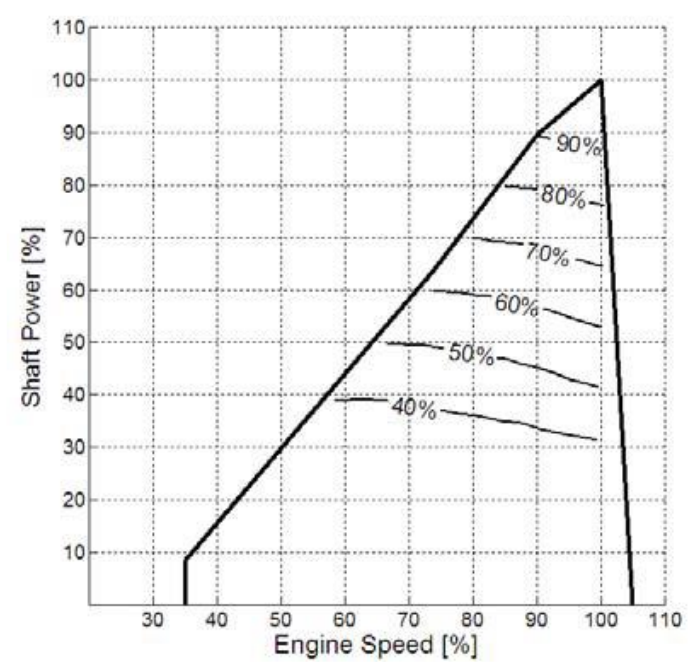

Fig. 8 Relative power change at the same fuel consumption levels as a function of relative engine speed [8]

For example, the $60 \%$ fuel consumption line indicates $60 \%$ of the fuel consumption at the maximum power. With higher engine speeds and low power consumption, the specific consumption is increasing as the performance drops, leading to a steeper reduction in the same fuel consumption curves when approaching the rated speed. The authors developed Eq. (1) to estimate the correlation between engine brake power performance, fuel consumption and engine speed:

$$
P_{B}=\left(\frac{m_{F}}{m_{F d}}\right)^{x}\left[a\left(\frac{m_{F d}}{m_{F}}\right)^{x} n_{E}^{3}+b\left(\frac{m_{F d}}{m_{F}}\right)^{y} n_{E}^{3}+c\left(\frac{m_{F d}}{m_{F}}\right)^{z} n_{E}\right]
$$

Where:

$P_{B}$ - current break power [kW]

$n_{E}$ - current engine speed [RPM]

$m_{F} / m_{F d}$ - current and design fuel consumption ratio (fuel rate)

$x, y, z$ - engine specific exponents $(\mathrm{x}=1.5 * \mathrm{y} ; \mathrm{z}=0.5 * \mathrm{y})$

a, $b, c$ - design fuel consumption curve coefficients

Index "d" refers to design value, i. g. the nominal engine values

The curve coefficients are calculated by having the $\mathrm{P}_{\mathrm{Bd}}-\mathrm{n}_{\mathrm{Ed}}$ relationship generally provided by the engine manufacturers and fitting a cubic polynomial curve according to the Eq. (2):

$$
P_{B d}=a n_{E d}^{3}+b n_{E d}^{2}+c n_{E d}
$$

With this in mind, the determination of $\mathrm{x}, \mathrm{y}, \mathrm{z}$ exponents is done so that the deviation from the available engine data at any point other than the design point is minimised. According to the authors, the method is extremely accurate. Making a calculation for a diesel engine that can be used in inland navigation, we got fairly acceptable results for the fuel consumption (with a deviation of $+/-5 \%$ ) [10].

\subsection{Estimated fuel consumption results for the current propulsion system}

The method presented in the previous section allowed us to generate the quasi-fuel map of the existing engine measured in the BKV 100 vessel. The results can be seen in Fig. 9, where not the values of the engine power but rather the torque is shown as this was the directly measured value. 


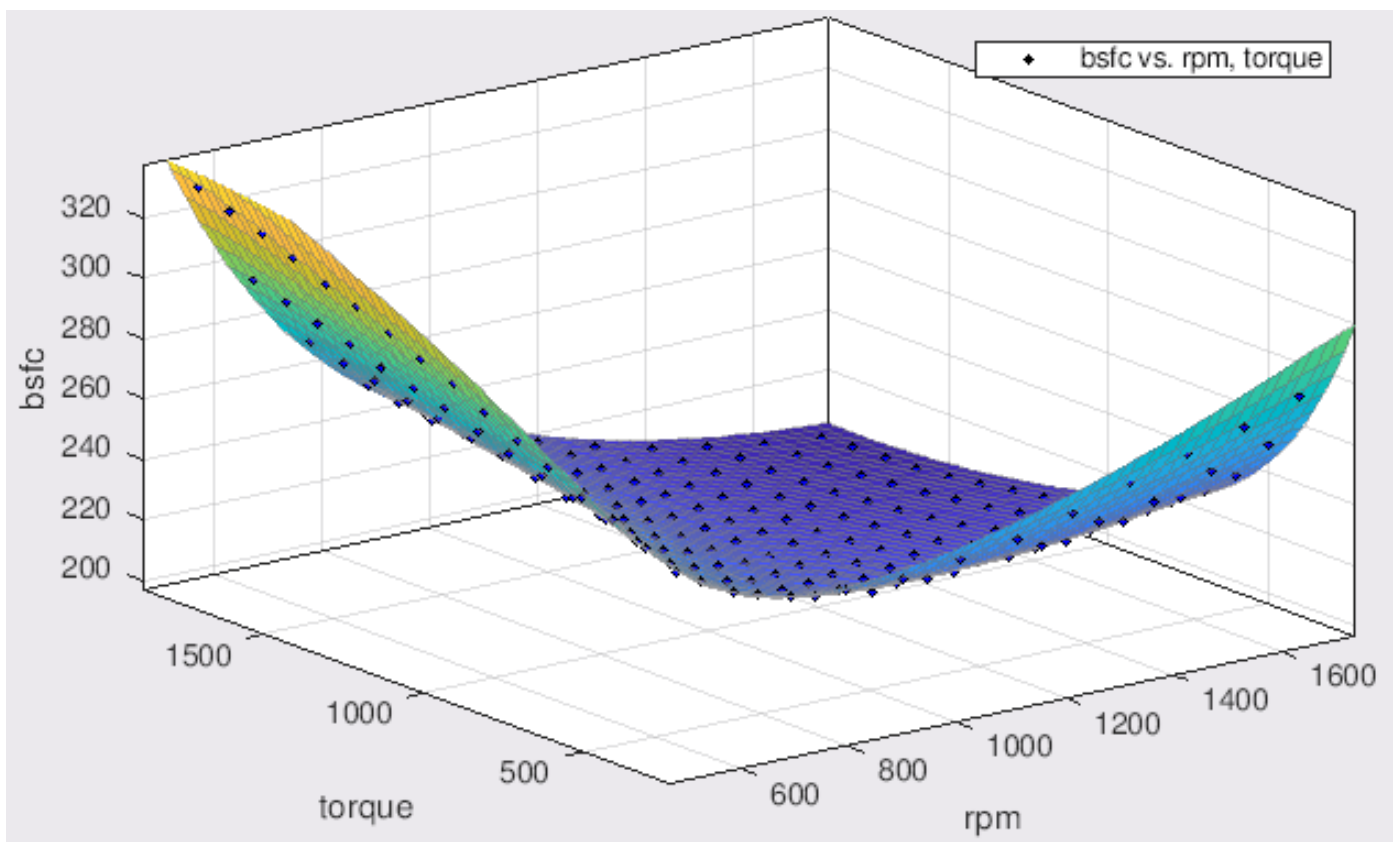

Fig. 9 Generated fuel map of Doosan L126TIM

The data of the generated table was imported into MATLAB to create a surface (Fig.9) and its polinomial equation. With even a third-order polinom, the R-square's value is above 0.99 , giving acceptable accuracy for further computations. The surface can be improved by choosing different exponent levels of the variables. MATLAB gives the equation of this surface with the required coefficients, so the estimated specific fuel consumption value can be determined for any torque-speed pair. The instantaneous BSFC (Brake specific fuel consumption) values at each measurement point can be determined using the recorded speedtorque pairs and the generated surface equation. The current fuel consumption can be obtained by multiplying the corresponding instantaneous power values (including the engine's generator surplus). Since the measurement sampling took place at the same intervals, it is easy to calculate the average consumption for the whole journey in either kilograms or liters.

After performing the calculations, the following results were obtained for the current engine (Tab. 1). The propulsion energy demand was calculated for each turn from the measured data, via integrating the area under the power curve. It already includes the energy demand of the engine's generator.

Table 1 Results of fuel and energy consumption calculations

\begin{tabular}{|c|c|c|c|c|c|c|c|}
\hline \multicolumn{4}{|c|}{ Upstream } & \multicolumn{4}{c|}{ Downstream } \\
\hline $\begin{array}{c}\text { Total energy } \\
\text { demand } \\
{[\mathrm{kWh}]}\end{array}$ & $\begin{array}{c}\text { Av. Fuel } \\
\text { cons. } \\
{[\mathrm{kg} / \mathrm{h}]}\end{array}$ & $\begin{array}{c}\text { Turn } \\
\text { time } \\
{[\mathrm{h}]}\end{array}$ & $\begin{array}{c}\text { Total Fuel } \\
\text { cons. } \\
{[\mathrm{kg} / \mathrm{l}]}\end{array}$ & $\begin{array}{c}\text { Total energy } \\
\text { demand } \\
{[\mathrm{kWh}]}\end{array}$ & $\begin{array}{c}\text { Av. Fuel } \\
\text { cons. } \\
{[\mathrm{kg} / \mathrm{h}]}\end{array}$ & $\begin{array}{c}\text { Turn } \\
\text { time } \\
{[\mathrm{h}]}\end{array}$ & $\begin{array}{c}\text { Total Fuel } \\
\text { cons. } \\
{[\mathrm{kg} / \mathrm{l}]}\end{array}$ \\
\hline 140.5 & 19.75 & 2.0 & $39.5 / 46.5$ & 73.0 & 15.90 & 1.5 & $23.86 / 28.1$ \\
\hline
\end{tabular}

\section{Alternative propulsion system options}

Based on the measured operating profile, the drive system may seem very oversized. Reasons for this, on one hand, could be that this vessel type originally was not designed for the public transport conditions in Budapest. On the other hand, in the case of a combination of 
high water levels, high vessel loads, and a sudden maneuver, it may be necessary to have much more power than measured in rather normal conditions. However, for most of the operation time, the propulsion system could be much more economical, so it may be worth at least considering an alternative propulsion system. In the following chapters, 4 promising alternatives are shown in more detail.

\subsection{Hybrid and Plug-in hybrid propulsion system}

One possibility is to build in a hybrid system. Of the different designs, the parallel design may be better in this case, because the serial system although it is simpler, it has more losses [11]. In this case it is still possible to plan at least two solutions. On the one hand, only the low-load periods (maneuvers, mooring) could be completed with a battery-powered electric motor, thus avoiding the diesel engine's high specific fuel consumption. Another option is to power the full downstream turn (which has lower energy demand) with the battery-powered electric motor. By this a part of the downstream diesel consumption can be saved, as on the other side, there is the need to charge the batteries, which also demands energy. Charging is again possible in two ways: with a generator driven by the main diesel engine through a gear or belt drive, and with shore-based quick chargers installed in ports. In the former case, there is extra fuel consumption due to the extra engine power to be spent on driving the generator, and in the latter case the cost of electricity for charging must be considered.

In the following, the components of such a system are described.

\subsubsection{Diesel engine}

The first step is to find a diesel engine with a lower power than the original, which covers the power of the maximum measured demand. Neglecting the power peaks, the max. constant power upstream fluctuated around $110 \mathrm{~kW}$, to which the power requirement of the engine's generator must be added $(5 \mathrm{~kW})$. Higher water levels and vessel load can lead to an increase in power demand, therefore it is worth calculating with an additional safety margin, which has been set (without any measurement basis) at $140 \%$, so min. a $161 \mathrm{~kW}$ motor must be installed. In addition, the torque of the new engine must be at least close to the torque values for the measured speeds (max. torque approx. $750 \mathrm{Nm}$ at $1650 \mathrm{RPM}$ ) and has to have the lowest possible specific fuel consumption values. The engines listed in Table 2 met best with the characteristics listed above (engine for diesel-electric solution is also shown in the table, see later chapter).

Table 2 Engine specifications [12] [13]

\begin{tabular}{|c|c|c|c|c|}
\hline & Unit & $\begin{array}{c}\text { Doosan L126 TIM } \\
\text { (original) }\end{array}$ & $\begin{array}{c}\text { Deutz BF6M1013MC } \\
\text { (hybrid \& PI hybrid) }\end{array}$ & $\begin{array}{c}\text { Deutz BF4M1013MC } \\
\text { (diesel-electric) }\end{array}$ \\
\hline Power & kW/HP & $294 / 400$ & $174 / 233$ & $100 / 134$ \\
\hline Speed & RPM & 2100 & 2300 & $1800(60 \mathrm{~Hz})$ \\
\hline BSFC & g/kWh & 215 & 226 & 230 \\
\hline
\end{tabular}

The method of calculating fuel consumption for the new engine is done in the same way as for the original engine. Diesel fuel bad winter behavior [14] could be a disadvantage for engines, but water is frozen when it happens; thus, it can be neglected. 


\subsubsection{Battery pack}

A key point is the selection and sizing of the battery pack. Lithium-ion batteries are generally used to drive vehicles, because they have the highest energy density. The life cycle of a lithium ion battery is the longest and its efficiency can reach 99\% if its state of charge (SOC) remains between $25-85 \%$ of its rated voltage level [15]. This means that only $60 \%$ of the installed capacity can be utilised for the propulsion. Keeping this in mind, a battery pack (containing fully enclosed 3.2 V Li-Ion battery cells connected in series) of min. $122 \mathrm{kWh}$ capacity can provide the required energy of $73 \mathrm{kWh}$ (see Tab. 1.). Given that approx. 15\% is the energy loss through the drive chain, the required capacity is approx. $140 \mathrm{kWh}$. However, only the used amount needs to be recharged, this is approx. $85 \mathrm{kWh}$. Considering the chargers' efficiency of $85 \%$, the energy consumption of the chargers is about $100 \mathrm{kWh}$.

\subsubsection{Electric motor and other system elements}

The system also requires an electric motor, frequency converter, PTI/PTO (Power take in / Power take off) gearbox and energy management. In the propulsion system of vehicles it is justified to use the asynchronous type of electric motors. However, for asynchronous motors, the required energy can only be provided by a 3-phase power supply. Neglecting the power peaks, downstream the max. constant power fluctuated around $95 \mathrm{~kW}$, to which the power requirement of the engine's generator must be added. It is again worth calculating with an additional safety margin of $140 \%$, so min. a $140 \mathrm{~kW}$ motor must be installed. Assuming $95 \%$ motor efficiency, the min. required rated power of the electric motor is about $147 \mathrm{~kW}$. When used as a generator, an asynchronous electric motor can operate at the same or higher efficiency $(\sim 97 \%)$. Considering the $110 \mathrm{~kW}$ power needed for upstream propulsion and that the installed power in case of the Deutz engine is $174 \mathrm{~kW}$, in theory approx. $60 \mathrm{~kW}$ is available for charging the batteries during upstream. Taking into account the power peaks, only a part of this power can be used. In 5.1 .2 it was stated that about $100 \mathrm{kWh}$ is necessary for full recharge of batteries, so the 2-hour long upstream period is enough - in optimal situation - for recharging.

In case of a plug-in hybrid, the quick charger(s) installed at the port(s) would charge the batteries, making a simpler drive and easier energy management. However, charging units can have a high initial investment cost and the price for electricity can also become a serious factor. It is possible to install one big charge station at the final station or more small charge stations at dedicated ports, however, the authors choose the first option.

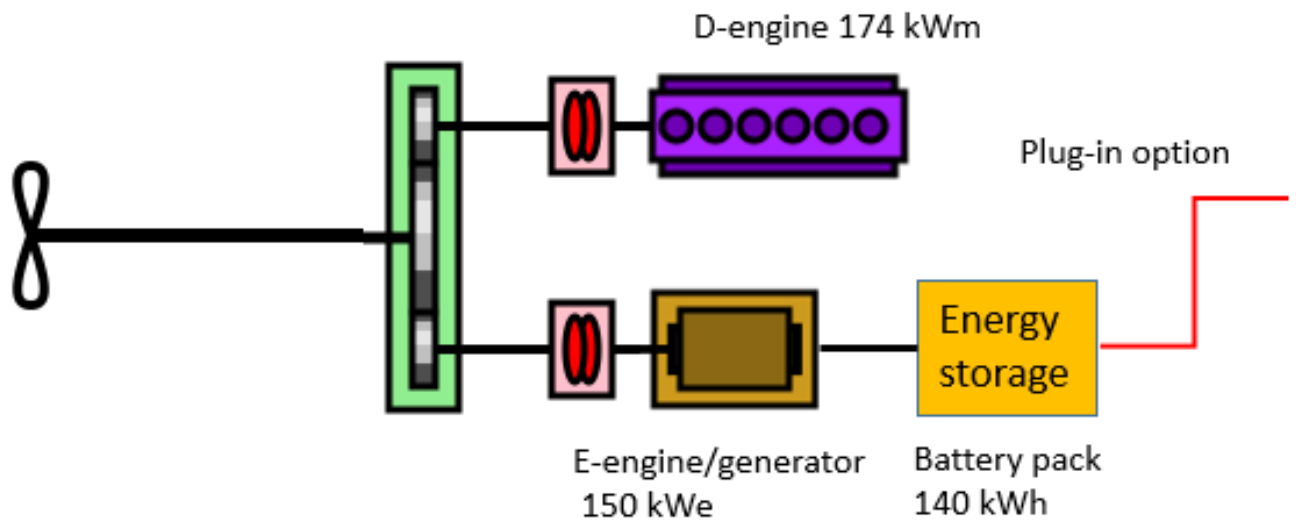

Fig. 10 Hybrid and Plug-in hybrid propulsion system 


\subsection{Diesel-electric propulsion system}

It is also possible to build a diesel-electric system. In this case there is no need for expensive chargers, PTI/PTO gearbox, battery packs. It requires only 2-3 low power gensets and the same elements in the electrical system as in the hybrid case. The only difference is that the power of the electric motor must be higher, as the max. power requirements of the whole route must be covered. In energy management, it is advisable to set the switching points a little bit higher, then the minimum of the specific fuel consumption curve. This usually occurs at 70-80\% load level. If the demand exceeds the corresponding power level, the next motor is turned on and so on. As in a diesel-electric system energy conversion take place several times and the number of system elements is also larger, the efficiency loss will increase. An additional loss of about $10 \%$ can be expected [16]. Because of the previously defined min. engine power $(161 \mathrm{~kW})$ and additional losses of the diesel-electric system min. $177 \mathrm{~kW}$ total power will be required. It is also important to note that the gensets have to be the type of variable speed, otherwise no reduction in consumption compared to the original system can be achieved. In this paper, the DE configuration was realized with 2 small power generator sets. The relevant details of the selected generator set are shown in the Table 2 .

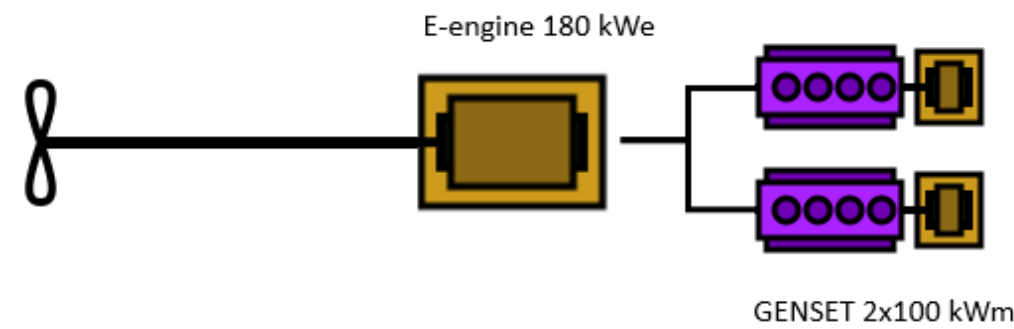

Fig. 11 Diesel-electric propulsion system

\subsection{All-electric propulsion system}

Thanks to the development of batteries, even larger ships can run on all-electric propulsion. This requires a larger battery pack, but usually there is enough space in a ship, and if the weight and volume of the batteries doesn't cause a major drawback, they can be used. Of course, there is also a need for a high-performance charging unit but today there are no technical barriers for this. Using the method already presented at the hybrid system description, a battery capacity of $420 \mathrm{kWh}$ is required for an up- and downstream route (one round-trip). The previously introduced $140 \%$ safety margin would be excessive here, as much of the reserve was only used to cover power peaks used for a short time. Here, taking a $120 \%$ margin into account, a battery pack with a capacity of approx. $500 \mathrm{kWh}$ was calculated. However, only the used amount needs to be refilled when charging the battery pack, which is approx. $250 \mathrm{kWh}$. With the previous charging efficiency, the energy consumption of the chargers would be approx. $295 \mathrm{kWh}$. The other components of the system are the same as in the diesel-electric configuration, but here no complex energy management is required, a simple battery management system (BMS) can be sufficient.

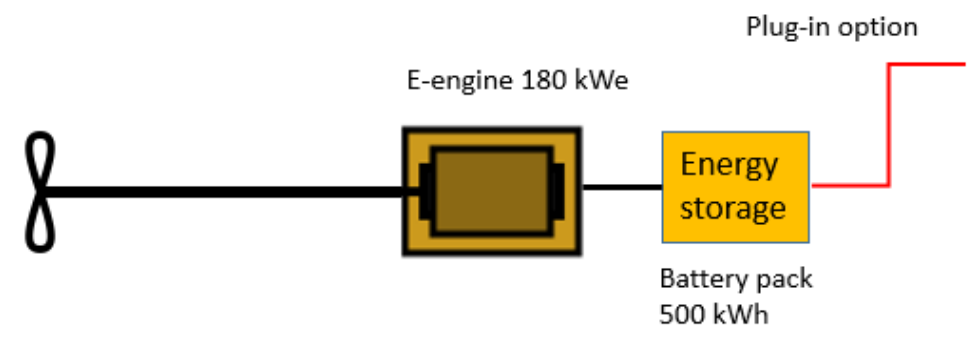

Fig. 12 Pure electric propulsion system 


\section{Cost analysis}

The cost analysis can be divided into two main parts:

- operating costs (only for the propulsion energy consumption)

- capital costs (only for system components)

\subsection{Operating costs}

The energy required for the propulsion, which can be provided by fuel or electricity, is taken into account here. The price of fuel is constantly changing, but fuels used in shipping are always much cheaper than road diesel. In a publication made in 2019 [17], a price of 0.70 $€ /$ liter is used as the basis for the return of investment (ROI) calculations, but two independent sources (BKV, MOL Hungary) also reported a lower value of $0.5 € /$ liter in relation to Budapest. The lower value was taken into account in the calculations. Since the Altosole method is able to estimate consumption with only a deviation of approx. 5\%, optimistic and pessimistic scenarios are also included in the payback time calculations. In the optimistic case, the calculated consumption of the existing configuration is increased by $5 \%$, while fuel consumption of the new system decreases by the same amount. In the pessimistic case, the opposite is true. In reality, consumption will most likely be between optimistic and calculated cases. This is because the current engine is more than 10 years old, so it certainly has a higher fuel consumption, what can be read from the technical data sheet.

According to Eurostat data, the costs of electricity in Hungary have been between 0.065 and $0.085 € / \mathrm{kWh}$ among non-household consumers in the last 5 years [18]. Based on the averages of the last 5 years, $0.075 € / \mathrm{kWh}$ can be expected. Due to the uncertainty, the price of electric energy was 0.5 cents lower in the optimistic case and 0.5 cents higher in the pessimistic case calculations. When using electricity, only the costs of recharging the energy are accounted.

\subsection{Capital costs}

A diploma thesis work provided the basis for estimating the value of investment costs [2]. The diploma project includes similar alternative drive system configurations based on the same measurement data. Therefore, for drive system elements having the same parameters or are parameter independent, there has been no change in the cost rate. In other cases, we made searching for the most accurate and actual costs. For the engines and motors, costs are calculated from [19]. Regarding batteries, it can be stated, that road- and marine battery systems differ very much [20]. One reason for this is the much higher security standards for marine applications which increase the system level costs. Technical requirements for inland navigation vessels are not that strict as for marine applications, but additional system costs obviously should be taken into account. However, not too much cost related data is publicly available for inland vessels. Therefore, based on [21], we use $120 € / \mathrm{kWh}$ for battery investment cost, knowing that return of investment would be even worse, if battery installation price is higher.

The BKV fleet consists of 8 similar vessels, in the PI hybrid calculations, we assumed 4 vessels and thus in the first round we take into account only a quarter of the cost of the charger to one vessel $(25 \mathrm{k} € / \mathrm{ship})$. For pure electric calculation a stronger charger unit is necessary. For the calculation we assume that electric network is sufficient for the charger, so power connection cost is neglected. Assuming same 4 vessels, we calculated in this case with $75 \mathrm{k} € /$ ship. In addition we calculated without gearbox cost in pure electric and diesel-electric 
case, because it is possible to use the current gearbox. Estimated gross capital costs are shown in Table 3.

Table 3 Estimated gross capital costs of propulsion systems

\begin{tabular}{|c|c|}
\hline Propulsion systems and their most important elements & $\begin{array}{l}\text { Estimated gross } \\
\text { capital costs } \\
\text { (EUR) }\end{array}$ \\
\hline \multicolumn{2}{|l|}{ Hybrid system } \\
\hline 4 stroke diesel engine (174 kW, Deutz BF6M1013MC) & 35000 \\
\hline Electric motor/generator (asynchronous, $150 \mathrm{~kW}$ ) & 18000 \\
\hline Drive system battery pack (140 kWh, Li-ion) & 17000 \\
\hline Gearbox (PTI/PTO) & 15000 \\
\hline Power and battery management system (CPU, BMS) & 30000 \\
\hline Total & 115000 \\
\hline \multicolumn{2}{|l|}{ Plug-in hybrid system } \\
\hline 4 stroke diesel engine (174 kW, Deutz BF6M1013MC) & 35000 \\
\hline Electric motor/generator (asynchronous, $150 \mathrm{~kW}$ ) & 18000 \\
\hline Drive system battery pack (140 kWh, Li-ion) & 17000 \\
\hline Gearbox (PTI/PTO) & 15000 \\
\hline Power and battery management system (CPU, BMS) & 30000 \\
\hline Quick charger (400 V, transformer+inverter) & 25000 \\
\hline Total & 140000 \\
\hline \multicolumn{2}{|l|}{ Pure electric system } \\
\hline Drive system battery pack (500 kWh, Li-ion ) & 60000 \\
\hline Electric motor (asynchronous, $180 \mathrm{~kW}$ ) & 21500 \\
\hline Battery management system (BMS) & 10000 \\
\hline Current gearbox & 0.000 \\
\hline Quick charger (700 V, transformer+inverter) & 75000 \\
\hline Total & 166500 \\
\hline \multicolumn{2}{|l|}{ Diesel-electric system } \\
\hline Diesel generator set (2 x $100 \mathrm{~kW}$, Deutz BF4M1013MC) & $2 \times 32000$ \\
\hline Electric motor (asynchronous, $180 \mathrm{~kW}$ ) & 21500 \\
\hline Current gearbox & 0.000 \\
\hline Power management system (CPU) & 10000 \\
\hline Total & 95500 \\
\hline
\end{tabular}




\section{Payback time calculations}

From the measurement it seems that a more economical solution for the propulsion of such vessels is possible. After estimating the operating and capital costs of the 4 alternative propulsion systems, it is interesting to determine the payback time. The vessel was built in 1986, so the acceptable payback period should not be too long, as there is a good chance that the vessel will be out from service in a reasonable time. The maximum acceptable limit may be around 15-20 years. Payback time was simply calculated as the ratio of capital costs and annual operational cost reduction. This cost reduction is calculated from fuel cost saving, which is reduced in some cases with electric energy consumption cost.

For most system components, the capital cost is considered as a one-time cost, since most of them have a lifespan of more than 20 years. Unfortunately, the battery pack is not one of them. Normally, lithium-ion batteries last for 800-2000 cycles without major loss of capacity. With careful battery management, this can be extended up to 9000 cycles [22], but above 2000 cycles only a fraction of the total capacity is available. If we count one cycle a day, this can be enough for up to 25 years. According to the current timetable for BKV vessels (which might change, however) a vessel completes 3 rounds per day for 8 months, but only 1 per day for the remaining 4 months. Thus, a total of approx. 800 cruises per year is done per vessel. In the case of hybrid and pure electric systems, this would mean that replacing the battery pack every 11 years is necessary. In this payback calculations we assume a 6-year replacement, which means appr. 5000 cycles. Hence, if a configuration with endless battery life has a payback time of 15 years, it would actually require at least three battery packs. This would increase the capital cost, resulting in a longer payback time. The iteration will end if the number of invested battery packs is higher than the payback time divided by 6 .

The following subsections contain the summary results of calculations and estimates that do not exceed the 30-year time limit. If the payback time exceeds 30 years, the capital cost cannot be determined (shown with "---" in the tables).

\subsection{Hybrid system}

Table 4 Payback calculation: Hybrid system

\begin{tabular}{|c|c|c|c|c|c|c|c|}
\hline Hybrid & $\begin{array}{c}\text { Current } \\
\text { Fuel cons. } \\
\text { Upstream } \\
\text { diesel }\end{array}$ & $\begin{array}{c}\text { Current } \\
\text { Fuel cons. } \\
\text { Downstream. } \\
\text { diesel }\end{array}$ & $\begin{array}{c}\text { Hybrid } \\
\text { Fuel cons. } \\
\text { Upstream. } \\
\text { diesel }\end{array}$ & $\begin{array}{c}\text { Hybrid } \\
\text { Fuel cons. } \\
\text { Downstream } \\
\text { electric energy }\end{array}$ & $\begin{array}{c}\text { Operating } \\
\text { cost } \\
\text { reduction }\end{array}$ & $\begin{array}{c}\text { Capital } \\
\text { costs }\end{array}$ & $\begin{array}{c}\text { Pay- } \\
\text { back } \\
\text { time }\end{array}$ \\
\hline calculated & 39.5 & 23.86 & 53.8 & 100 & 4.639 & --- & exc. \\
\hline optimist & 41.87 & 25.29 & 50.57 & 100 & 8.051 & 149 & 18.51 \\
\hline
\end{tabular}

The electric motor functions as a charger in the hybrid case, so there is no need for a shore charger unit. However, charging requires extra power from the motor, so you can see in the Table 4 a big surplus in fuel consumption at upstream with the same motor. Due to the size of the surplus, the return on investment in an optimistic case would take 18.5 years, but in other cases it would take more than 30 years. 


\subsection{Plug-in hybrid system}

The Table 5 shows that with the new, less powerful engine, lower fuel consumption can be achieved on an upstream voyage and the energy consumption in downstream is already electric, as batteries power the vessel. Capital costs include a quick charger, which one-time cost is very high, so it only makes sense to invest in it if it is used by several ships.

Table 5 Payback calculation: Plug-in hybrid system

\begin{tabular}{|c|c|c|c|c|c|c|c|}
\hline $\begin{array}{c}\text { Plug-in } \\
\text { hybrid }\end{array}$ & $\begin{array}{c}\text { Fuel cons. } \\
\text { Upstream } \\
\text { diesel }\end{array}$ & $\begin{array}{c}\text { Fuel cons. } \\
\text { Downstream } \\
\text { electric en. }\end{array}$ & $\begin{array}{c}\text { Oper. } \\
\text { cost } \\
\text { red. }\end{array}$ & $\begin{array}{c}\text { Cap. } \\
\text { costs }\end{array}$ & $\begin{array}{c}\text { Pay- } \\
\text { back } \\
\text { time }\end{array}$ & $\begin{array}{c}\text { Cap. costs } \\
\text { without } \\
\text { charger }\end{array}$ & $\begin{array}{c}\text { Payb. time } \\
\text { without } \\
\text { charger }\end{array}$ \\
\hline $\mathrm{kg}$ & $\mathrm{kWh}$ & $\mathrm{k} € /$ year & $\mathrm{k} €$ & year & $\mathrm{k} €$ & year \\
\hline calculated & 36.7 & 100 & 6.75 & --- & exc. & 183 & 27.11 \\
\hline optimist & 34.50 & 100 & 10.0 & 174 & 17.27 & 149 & 14.79 \\
\hline
\end{tabular}

Onshore recharging of batteries significantly reduces the profit from fuel savings, so even in an optimistic case, the investment pays off only after 17 years. By financing the charging unit from an external source (state, EU), the return on investment would be already 15 years in an optimistic case and 27 years in the calculated case, but it would be still over 30 years in other cases.

\subsection{Pure electric system}

Table 6 Payback calculation: Pure electric system

\begin{tabular}{|c|c|c|c|c|c|c|c|}
\hline $\begin{array}{c}\text { Pure } \\
\text { electric }\end{array}$ & $\begin{array}{c}\text { Fuel cons. } \\
\text { Upstream } \\
\text { electric en. }\end{array}$ & $\begin{array}{c}\text { Fuel cons. } \\
\text { Downstream } \\
\text { electric en. }\end{array}$ & $\begin{array}{c}\text { Oper. } \\
\text { cost } \\
\text { red. }\end{array}$ & $\begin{array}{c}\text { Cap. } \\
\text { costs }\end{array}$ & $\begin{array}{c}\text { Pay- } \\
\text { back } \\
\text { time }\end{array}$ & $\begin{array}{c}\text { Cap. costs } \\
\text { Without } \\
\text { Charger }\end{array}$ & $\begin{array}{c}\text { Payb. time } \\
\text { without } \\
\text { charger }\end{array}$ \\
\hline kWh & $\mathrm{kWh}$ & $\mathrm{k} € / \mathrm{y}$ & $\mathrm{k} €$ & year & $\mathrm{k} €$ & year \\
\hline calculated & 195 & 100 & 12.5 & --- & exc. & 211.5 & 16.93 \\
\hline optimist & 195 & 100 & 15.56 & 346.5 & 22.27 & 91.5 & 5.88 \\
\hline
\end{tabular}

Based on the Table 6, this combination seems to be the 2 nd worst solution, as even in an optimistic case, the payback period is 22 years, but this would already be an investment of almost 700 thousand euros for 4 ships. Financing the cost of the charging unit from an external source (state, EU) would return the investment in 6 years in the optimistic case and in 17 years in the calculated case. In the pessimistic case it would still be over 30 years.

\subsection{Diesel-electric system}

Table 7 Payback calculation: Diesel-electric system

\begin{tabular}{|c|c|c|c|c|c|}
\hline $\begin{array}{c}\text { Diesel - } \\
\text { electric }\end{array}$ & $\begin{array}{c}\text { Fuel cons. } \\
\text { Upstream } \\
\text { diesel }\end{array}$ & $\begin{array}{c}\text { Fuel cons. } \\
\text { Downstream } \\
\text { diesel }\end{array}$ & $\begin{array}{c}\text { Operating cost } \\
\text { reduction }\end{array}$ & $\begin{array}{c}\text { Capital } \\
\text { costs }\end{array}$ & $\begin{array}{c}\text { Payback } \\
\text { time }\end{array}$ \\
\hline kg & $\mathrm{kg}$ & $\mathrm{k} € /$ year & $\mathrm{k} €$ & year \\
\hline optimist & 36.38 & 21.6 & 1.485 & --- & exc. \\
\hline
\end{tabular}


The diesel-electric configuration summary table (Table 7) shows that the system's capital cost is much lower than in previous cases. However, in the pessimistic case in terms of fuel consumption, it would perform worse than the current conventional propulsion. The payback time would be roughly 19 years in an optimistic case.

\section{Conclusion}

Budapest's public water transport fleet is not in an easy position, as a lot of circumstances can affect the power demand of vessels. At first look, alternative drive systems could be expected as promising not only from the environmental point of view. Thus, it was worth to analyse some alternative drive systems.

In this article, 4 different configurations of 3 systems were examined not only in terms of fuel/energy consumption but also in terms of expected costs. Based on the results, it can be stated, that neither of the cases provide early return of investments.

A major disadvantage of onshore charging solutions is the high investment cost of the charging unit. Even if divided between 4 vessels, no early return is expected in the plug-in hybrid and pure electric cases. A much earlier return can be expected if a grant could cover the charging unit's full cost, even with fewer vessels. On the other hand, using onshore electricity as a power source greatly reduces the operational costs, compared to those cases, in which electricity is produced by burning fuel oil. The reason for this is to be found in the lower cost of electricity providing the same amount of energy. This also emphasizes the importance of how the charger could be financed.

Based on these data, it can be said that switching to any alternative drive system would not be easy or risk-free. However, the payback time can vary greatly as investment costs decrease. It is possible that the operator may have access to the components at a lower cost than here estimated values. Fuels are sure to become more expensive over time, while lithium-ion batteries' cost is on a declining trend. Both factors have a positive effect on the payback time. In the article, the authors did not account for maintenance, design, and installation costs because they are very difficult to quantify in general. The latter two would certainly increase the payback time, but not significantly (max. 5\%). The systems with a battery pack require less maintenance. Increasing the proportion of battery power in total demand, decreases the maintenance costs compared to a traditional system. In the case of an alternative drive system, the redundancy of the drive system increases. Additional benefits include lower noise and emissions, which can attract more passengers to the ships.

As a final conclusion, alternative drive systems for inland vessels can result in reduction of fuel consumption and operational costs, but one has to pay for this on the investment side, which may prevent the refitting. This also shows that the optimisation of the propulsion system should be a major consideration when designing a ship.

\section{REFERENCES}

[1] Stichting Projecten Binnenvaart (2016): D1.1 List of operational profiles and fleet families, PROMINENT, 633929, SWP 1.1

[2] Zöldy M., Zsombók I.,(2019) Modelling fuel consumption and refuelling of autonomous vehicles MATEC Web Conf. Volume 235, 2018 https://doi.org/10.1051/matecconf/201823500037

[3] Horváth G. Á. (2018): BKV 100-as közforgalmú személyszállitó hajó energetikai elemzése, BME, VRHT-M-H-2018-1

[4] http://termtud.akg.hu/okt/7/viz/7vizfoly.htm 
Zalacko Roland, Dr. Zöldy Máté, Dr. Simongáti Győző
Comparison of alternative propulsion systems A case study of a passenger ship used is public transport

[5] Dr. Simongáti Gy., Hargitai L. Cs., Zalacko R. (2018): Operational profile of inland public transport vessel, VSDIA conference 2018, Budapest

[6] www.hydroinfo.hu/Html/archivum/archiv_tabla.html

[7] Zöldy, M (2019) Improving Heavy Duty Vehicles Fuel Consumption With Density And Friction Modifier Int J Automot Technol. 2019;20(5):971-978. https://doi.org/10.1007/s12239-019-0091-y

[8] Wu Z. (2017): Comparison of fuel consumption on a hybrid marine power plant with low-power versus high-power engines, Msc thesis, NTNU-Trondheim https://doi.org/10.1115/OMAE2018-77959

[9] Altosole M., Figari M. (2011): Effective simple methods for numerical modelling of marine engines in ship propulsion control systems design, Journal of Naval Architecture and Marine Engineering, https://doi.org/10.3329/jname.v8i2.7366

[10] Zalacko R., Dr. Simongáti Gy., Dr. Zöldy M. (2020): Comparative study of two simple BSFC estimation methods, Brodogradnja Volume 71/3, https://doi.org/10.21278/brod71302

[11] Bennabi N., Charpentier J. F., Menana H., Billard J. Y., Genet P. (2016): Hybrid propulsion system for small ships: context and challenges, Conference: ICEM2016, https://doi.org/10.1109/ICELMACH.2016.7732943

[12] Doosan L126TI propulsion engine data sheet

[13] Deutz 1013M propulsion engine data sheet

[14] https://batteryuniversity.com/learn/article/how_to_prolong_lithium_based_batteries

[15] Zöldy M. (2019) Investigation of Correlation Between Diesel Fuel Cold Operability and Standardized Cold Flow Properties, Periodica Polytechnica Transportation Engineering. https://doi.org/10.3311/PPtr.14148

[16] Herdzik J. (2013): Problems of propulsion systems and main engines choice for offshore support vessels, Scientific Journals Maritime University of Szczecin, 36(108) z. 2 pp. 45-50, ISSN 1733-8670

[17] Interreg Danube Transnational Programme Grendel (2019): Gas and Gas-electric propulsion, Fact Sheet No. 1

[18] https://appsso.eurostat.ec.europa.eu/nui/show.do?dataset=nrg_pc 205\&lang=en

[19] TNO (2018): D2.8 / D2.9 Standardized model and cost/benefit assessment for right-size engines and hybrid configurations, PROMINENT, 633929, WP 2

[20] https://marine.man-es.com/docs/librariesprovider6/test/batteries-on-board-ocean-going-vessels.pdf

[21] Penisa N. X., Castro T. M., Pascasio J. D. A., Esparcia E. A., Schmidt O., Ocon J. D. (2020): Projecting the price of lithium-ion NMC battery packs using a multifactor learning curve model, Energies, 13, 5276; https://doi.org/10.3390/en13205276

[22] Peng W., Richard B. (2016): Marine propulsion using battery power, Shipping in Changing Climates Conference, Newcastle

Submitted: 23.12.2020. Zalacko Roland, rzalacko@ vrht.bme.hu

Dept. of Aeronautics, Naval Architecture and Railway Vehicles

Accepted: $\quad$ 19.05.2021. Budapest University of Technology and Economics

Budapest, Hungary

Corresponding author: Dr. Zöldy Máté, mate.zoldy@auto.bme.hu

Dept. of Automotive Technologies

Budapest University of Technology and Economics

Budapest, Hungary

Dr. Simongáti Győző, gysimongati@vrht.bme.hu

Dept. of Aeronautics, Naval Architecture and Railway Vehicles

Budapest University of Technology and Economics

Budapest, Hungary 